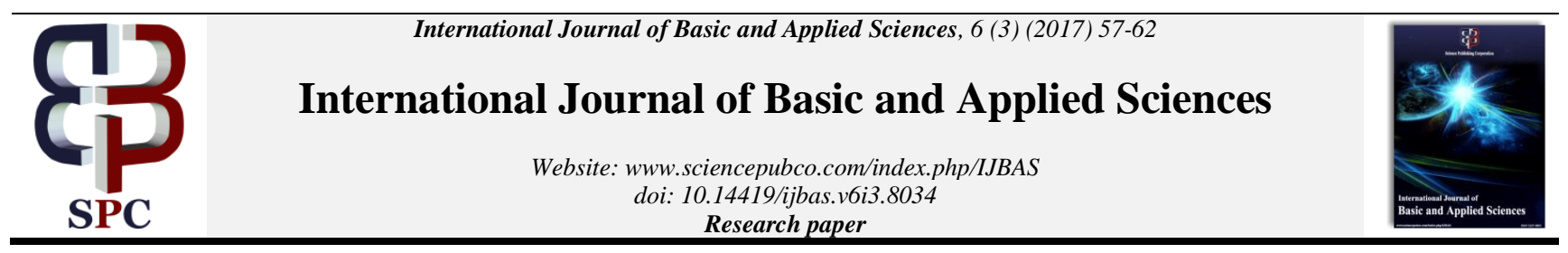

\title{
A minireview on the use of wavelet analyses on physiological signals to diagnose and characterize ADHD
}

\author{
Benito de Celis Alonso *, Javier Miguel Hernández López, José Gerardo Suárez García \\ , Eduardo Moreno Barbosa
}

Facultad de Ciencias Físico-Matemáticas, BUAP, Puebla, Pue., México

*Corresponding author E-mail: bdca@fcfm.buap.mx

\begin{abstract}
Attention deficit hyperactivity disorder (ADHD) is one of the most prevalent psychological disorders in pediatric patients. The actual golden standard of ADHD diagnosis is based on conclusions derived from clinical questionnaires. Nowadays, there is no quantitative measurement performed with any imaging system (MRI, PET, EEG, etc.) that can be considered as a golden standard for this diagnosis. This issue, is highlighted by the existence of international competitions focused on the production of a technological (quantitative) solution capable of complementing ADHD diagnosis (ADHD-200 Global Competition). Wavelet analysis, on the other hand, is a flexible mathematical tool that can be used for information and data processing. Its advantage over other types of mathematical transformations is its ability to decompose a signal into two parameters (frequency and time). Based on the prevalence of ADHD and the extra functionality of wavelet tools, this review will try to answer the following question: How have wavelet analyses been used to complement diagnosis and characterization of ADHD? It will be shown that applications were not casual and limited to time-frequency decomposition, noise removal or down sampling of signals, but were pivotal for construction of learning networks, specific parameterization of signals or calculations of connectivity between brain nodes.
\end{abstract}

Keywords: ADHD; EEG; MRI; Physiological Signals; Wavelet Analysis.

\section{Introduction}

Attention deficit hyperactivity disorder (ADHD) is the most common neuropsychiatric disorder in children and adolescents worldwide, with a prevalence of $5.29 \%$ according to current meta-analysis [1]. It affects the patient's brain at all levels (anatomically and functionally) with clear effects on the dopaminergic system (especially substantia nigra and the ventral tegmental area) and other brain areas like the cerebellum and the frontal lobes. Children with ADHD have trouble paying attention, controlling impulsive behaviors and, in some cases, are overly active.

Nowadays, the golden standards for ADHD diagnosis are clinical evaluations, which include tests like ADHD-rating scales or Conners together with school reports and a clinical history. As diagnosis is based on the interpretation of results and experience of the medical doctor, the issue of misdiagnosis must be raised in some situations. In fact, a study of the sensitivity and specificity of these tests on their own gave values, which were hardly over $60 \%$ [2]. These values increased to $75 \%$ when more than just one test was used (authors of this review would like to manifest that they believe these results are quite low and believe that the accuracy of properly medical trained professional is higher). Nevertheless, what is obvious is that there is a lack of a quantitative diagnostic tool that would certainly complement and improve diagnosis rates [3]. This argument is supported by the existence of international competitions like the ADHD 200 global competition (http://fcon_1000.projects.nitrc.org/indi/adhd200/results.html) specifically celebrated to develop diagnostic classification tools for ADHD.
Wavelet analysis uses a series of mathematical functions (Fig. 1A) named wavelets that fulfill a series of constraints such as being finite and having an area under the curve equal to a finite number. Wavelet analysis is based in the concept of convolution. A given mother wavelet is superimposed on a given point of a time series and calculations of the convolution values are performed moving and deforming the original wavelet (daughter wavelets) over the signal with time (Fig. 1. B-D). The point where the convolution is maximal indicates where that signal is most similar in shape to that of the mother wavelet (Fig. 1. E). The pictorial representation of the wavelet analysis of a given signal is done with a scalogram on which convolution values are represented against scale and time deformations of the mother wavelet (Fig. 1.F). It is because of all this, that the most basic applications of wavelets are to look for specific patterns in signals. Other relevant properties of wavelet analysis are the fact that their calculations can be undone. During these processes wavelets can be used to filter signals by keeping just certain parts of the transformed data, store the information of the signal in reduced space as not all the signal is saved, or used to de-noise information eliminating certain coefficients known to be associated with spurious signals. All the applications described above can be performed on 3D or 4D images expanding wavelet applicability to almost all sets of data. Nevertheless, and as implicitly seen in the scalogram description, the main advantage of wavelet analysis is that it can extract simultaneously time and frequency information of an analyzed signal. This contrasts with other more common transformations like Fourier, which just give frequency information. In other words, wavelet analysis is not just able to indicate how frequencies change but also when they do so. Because of this, these mathematical tools are best suited for the analysis of non-stationary signals, and are capable of deconstructing complex signals 
into basic ones of finite bandwidth, and then reconstructing them again with very little loss of information. Practically, this means that there is little-to-no signal leakage or phase-shifting of the original signal when you decompose it.

(A)

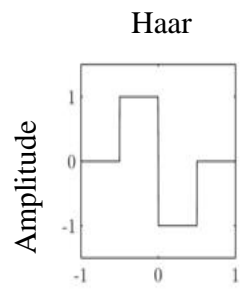

Mexican Hat

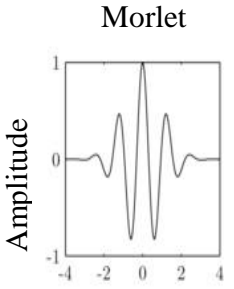

(B)
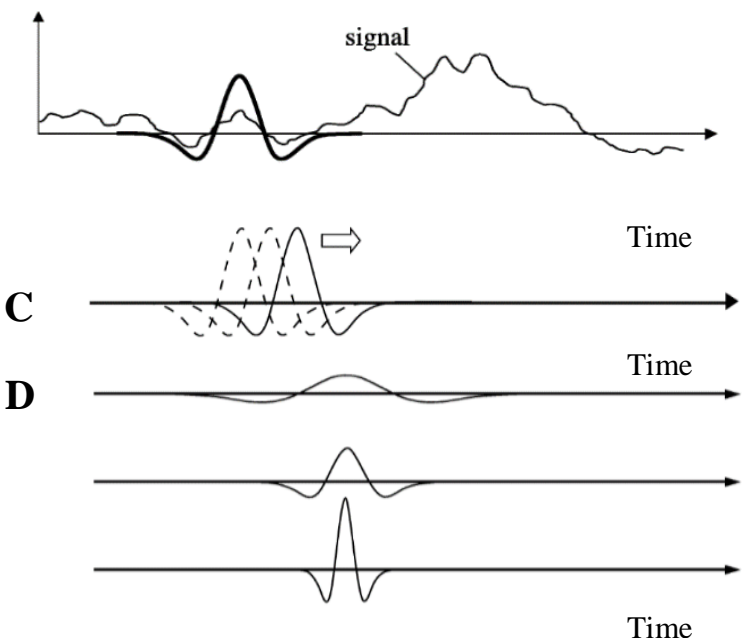

(E)

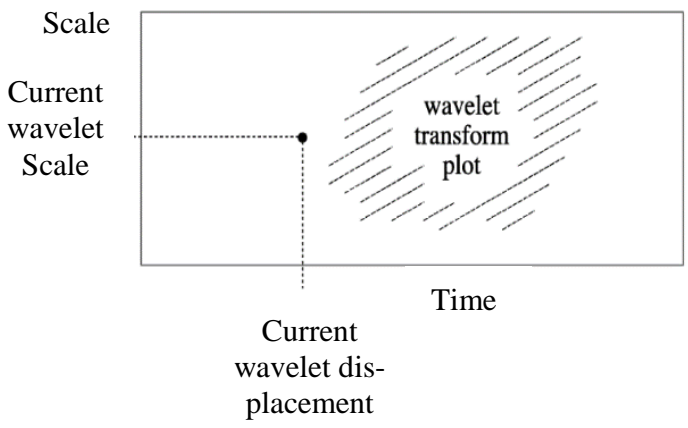

(F)

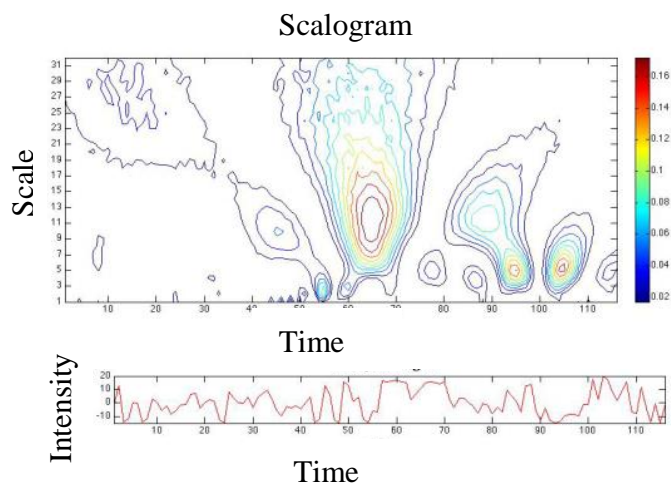

Fig. 1: Wavelet Introductory Theory.

This figure presents how a basic analysis is performed with wavelets. 1A shows three examples of mother wavelets. 1B-D presents the displacements over time (B \& C) and deformations (D) of the mother wavelet that are used in these kinds of analyses. $1 \mathrm{E}$ shows a point in which an associated correlation value between daughter wavelet and a random signal is found. $1 \mathrm{~F}$ is a scalogram with the wavelet analysis results for the signal pictured underneath it.
Because of the prevalence of the disorder, the fact that ADHD is not easy to diagnose and the flexibility for information extraction and processing of wavelet techniques; authors feel that a review on this field would be of great interest. Therefore, this commentary will focus specifically on how wavelet analyses are used on results from brain imaging technologies and their contribution to the diagnosis and characterization of the physiology behind ADHD.

We performed a search of articles cited in PubMed, Web of Science, Google Scholar and Scopus from 1995 to 2016 using the following MeSH terms (Medical Subject Headings): "Wavelet" and "ADHD". Considering all data bases, a total of 1053 papers and proceedings were found (repeated works were considered as a single find). After checking (one by one) that they indeed were using wavelet analysis on ADHD data a total of 19 articles remained, which are presented and discussed in this commentary. Data is presented dividing findings by the neurological technique used to obtain information from ADHD patients.

\section{Wavelet analysis applied to ADHD patients using electroencephalography (EEG)}

There is an extensive body of work in which EEG is used to try to diagnose ADHD (e.g. [4]). Nevertheless, there is not that much if analysis with wavelets is considered. Initial work appears as early as 1997 [5]. In it, researchers used wavelets to extract information from auditory evoked potentials. They tried to distinguish between two groups of ADHD and Control patients using a classifying program which functioned through two stages. A first step, in which wavelets were used to extract and parameterize the EEG signals and a second step, in which classification was performed. The highlight of their setup was that this was a self-learning network in which feature selection with wavelets was performed simultaneously to training. Authors report an $80 \%$ of success in differentiating volunteers.

Other examples of wavelet applications in EEG studies can be found in 2001 Heinrich et al. [6]. Here authors built a wavelet network to mimic event-related potentials (ERP) obtained from EEG measurements. They summed Morlet wavelets of different frequencies, shifting values and scales. To the standard parameters that can be modified, they also added a weighting factor to each wavelet. This allowed a more exact and easy to understand parameterization of the modeled ERP. Results from this study allowed researchers to discover different time dynamics between groups after a 5-minute auditory stimulation. Larger numbers of omission errors as well as larger frontal lobe negativity results were reported for ADHD patients.

As mentioned in the introduction, wavelets are best for the analysis of non-stationary signals, providing a way of tracking the evolution of periodic activity over time. For example, Yordanova et.al. [7] used wavelet transform on EEG signals (auditory gamma band) when comparing healthy to ADHD volunteers during an auditory task. The ability of wavelets to analyze signals at different time points is crucial here as gamma bursts appear randomly in time after stimulus. Differences in these phase-locked bands were found in right side stimulations in which ADHD volunteers had larger signals. This, according to authors, was an indication of alterations in the early mechanisms of audition for these patients. This result was indirectly supported by Gross et al. [8]. In a more recent work, theta oscillations analyzed and obtained with wavelets when comparing three groups (Control, ADHD and Tick Disorder), showed that spontaneous and event-related oscillations were unique to the ADHD patients while early theta responses were common to all three groups [9]. In a more recent study, this same research group addressed the differences in performance accuracy of default network structures between an ADHD and Control groups. They found that both groups presented multi-second behavioral fluctuations every $12 \mathrm{~s}$ but the ADHD group also presented these differences in a secondary oscillation with a 20-30 s period [10]. Finally, in a 2013 paper, they reviewed previous work on the use of wavelet analysis on ADHD patients, and included a small study in which the mu 
band (8-12 s) was used when comparing motor function of ADHD and Control patients [11]. Their findings indicated that even if excitability of motor cortex was similar between groups, inhibition in complex tasks was different being a possible source of motor processing deficiencies for ADHD patients. In all these works, wavelets were mainly used because of their time frequency signal decomposition capacities.

An example of a different application of these tools, is information extraction using wavelets in a recent work by Ahmadolou et al Here a novel wavelet analysis on EEG signals was used to diagnose ADHD patients. This was done using wavelet chaos techniques [12] which extracted non-linear and chaotic features of the EEG signals. This way, they found foci of high and low connectivity in brain regions, which corresponded to certain EEG electrodes, which were different for ADHD and Control subjects. A classification of the connectivity results allowed them to present a success rate of $96 \%$ in diagnosis of ADHD according to the authors [13].

Alexander et al. [14] have shown that ADHD patients showed on the $\mathrm{P} 3$ electrode decreased activity when compared to healthy counterparts when performing the continuous performance task. These differences disappeared after medication. The activity of the low frequencies measured was inversely related to psychological measurements of hyperactivity. The wavelet analysis performed here used a Morlet mother wavelet on EEG data. It was used to fist filter signals at 32 different frequency values logarithmically distributed between 0.2 and $32 \mathrm{~Hz}$. With this information, the phase and amplitude change in each electrode was calculated with respect to a phase leading electrode [15].

Seung Lee et al. have also used wavelet analysis on EEG signals to increase diagnostic accuracy of ADHD. They first used wavelets to de-noise data. Then, coefficients from EEG signals were calculated with multi-level discrete wavelet analysis, and results were selfclustered. The use of the sym7 wavelet was the most successful when feeding data to the clustering subroutines Lee et al. [16]. The accuracy of diagnosis with this setup was $60 \%$. Nevertheless, and considering the high dependence of clustering on the wavelet used for analysis, new techniques pointing at improving this selection were developed increasing accuracy of the results by $15 \%$ [17]. Finally, in a study by Hillard et al. [18] EEG signals were also filtered and manipulated using wavelet analysis. The objective was to find changes in relative power of the measured signals related to a non-pharmacological neuro-feedback treatment developed to improve alertness and focus in ADHD patients. By using the Morletmother wavelet, filtered signals (frequencies between 2 and $45 \mathrm{~Hz}$ ) from an EEG electrode positioned in the prefrontal cortex (EEG(FPz)) were separated into 128 components, which were further filtered using a Harris window configuration. The produced signals were then summed obtaining a de-noised and filtered signal. The obtained signals had to be over a certain threshold value that would allow scientists to confirm that volunteers were, in fact, focused or alert at any given time point during their treatment (one session usually lasted 25 minutes). Results showed that the changes (total duration) in alertness and focus levels measured with EEG could be found as soon as a few minutes after starting the first of the twelve session of this psychological treatment.

\section{Wavelet analysis applied to ADHD patients using magnetoencephalography (MEG)}

In a recent study by Docksteader et al. [19] wavelet analysis based on the Morlet mother wavelet was used on MEG data to obtain the phase-locked and non-phase-locked changes in power at different frequencies over time. These analyses allowed comparison of ADHD with Controls in the primary and secondary somatosensory brain regions. They showed decrease de-synchrony in the alpha bands and decreased synchrony in the beta band for ADHD patients in both regions.

In another study by Franzen et al., the Gabor wavelet was used to obtain phase values of the wavelet convolution of the MEG signal at a given seed frequency after filtration. These values were then used to assess the synchronicity of activity of the different measurements from MEG nodes or pair of MEG nodes. A conclusion of this study was that ADHD patients presented different connectivity between sections from the default mode network when compared with healthy controls. These differences, as in other studies, were higher and lower in different cases depending on the regions considered [20].

\section{Wavelet analysis applied to ADHD patients using functional MRI}

Work in which wavelet analysis has been applied to magnetic resonance (MR) signals is sparse. When looking for analysis of blood level oxygen dependent (BOLD) signals a few studies stood out. In a functional magnetic resonance imaging (fMRI) study on humans [21], volunteer's emotional reaction scores to meditation, neutral or emotional memories were assessed. Here wavelets were involved in the assessment of low frequency physiological noise fluctuations of BOLD signals from the cerebellum. Cerebellum was chosen as it is a brain area usually affected by ADHD and other psychiatric disorders. A wavelet scaling component was calculated for signals fluctuating between 0.015 and $0.5 \mathrm{~Hz}$. A correlation between this component and emotional measurements was found exclusively in the posterior inferior vermis and no other cerebellar regions. This correlation was lost once medication (Methylphenidate) was given to volunteers. Authors, hypothesized on this single finding that wavelet analysis was an appropriate tool to study the long BOLD time series that appear in cerebellar-thalamic-cortical functional studies of any kind of psychiatric disorder, but specifically in ADHD.

In a recent study, the relation between low frequency fluctuations of BOLD signal, response time to a task (RT) and ADHD symptom ratings were measured [22]. This work was based on previous projects in which a large inter-subject variability of RT signals, and ADHD symptoms was established. Using Morlet wavelet analysis on RT data obtained during tests designed to assess inattention and hyperactivity in ADHD patients, different frequency bands obtained from the analysis showed a strong correlation with scores form the ADHD tests performed.

\section{Wavelet analysis applied to ADHD patients using MRI resting states}

Recently, Romero et al. [23], and González et al. [24] presented some attempts on differential diagnosis of ADHD and Control pediatric patients using wavelet analysis with promising results. In them, application of the Mexican Hat wavelet to BOLD resting state images of a single brain slice crossing cerebellum and frontal areas showed (previous sex and age separation) the ability to distinguish between Controls and ADHD patients. In their studies, integrated spectrums of the whole image (integration of all positive wavelet transform results for all the image) were presented vs. scales. Results showed that control patients had larger values of this parameter than their ADHD counterparts. This was done with a success rate of $85 \%$. Two years later, Suárez et al. [25] used a similar wavelet analysis on resting state signals of a given brain ROI, to distinguish Controls from ADHD patients. Here, wavelet analysis was also used to parametrize signals and model predictors based on these values. Experiments were performed comparing four different wavelets (Coiflets 1, Daubechies 2, Daubechies 3 and Mexican Hat). Results from their analyses concluded that brain areas that presented maximal differences between groups were: frontal orbitofrontal region, calcarine sulcus, lingual gyrus, superior occipital gyrus, postcentral gyrus, temporal pole, crus I and II. Their success rate segregating both groups was close to $84 \%$.

In a paper from 2015, Reiss et al. [26] showed their results for the ADHD challenge in which they analyzed resting state data (ReHo and ALFF images) of patients with ADHD using wavelet analysis. Even if initially, they found that ADHD was highly correlated with 
ALFF images, they demonstrated that this correlation was basically mediated by the sex and age of participants. The study highlighted the importance of matched in age and gender studies in the field if a comparison was to be done. Their wavelet analysis was focused on correlating images and image features with scalar alike clinical features (scalar-on-image regressions). Even if no accuracy value was provided, they concluded that information derived directly from images could not compete in accuracy with scalar information derived from wavelet analyses of images.

\section{Wavelet analysis applied to ADHD patients using other techniques}

In work from the Di Martino et al. [27] a temporal series was formed with the response times of ADHD and Control volunteers to a task (Eriksen Flanker task). Data was recorded every $3 \mathrm{~s}$ for a total experimental time of $930 \mathrm{~s}$ and then was analyzed. They used in this decomposition analysis a Morlet continuous wavelet. They found that at high frequencies $(0.027$ and $0.073 \mathrm{~Hz})$ there was a finer magnitude of the spectral component in ADHD children when compared to Controls. Furthermore, they found that the variability of this parameter in ADHD patients was also finer than in Controls.

Table 1 Summary Review. This table presents a summary of the articles included in this review. The information presented in its different columns is: Author's name, year of publication, mother wavelet used for analysis, neurological technique used, main finding, wavelet and brain regions studied.

Table 1: Summary of Review

\begin{tabular}{|c|c|c|c|c|c|c|}
\hline Authors & Year & Mother wavelet & $\begin{array}{l}\text { Neurological } \\
\text { technique }\end{array}$ & Main finding & Wavelet use & $\begin{array}{l}\text { Brain regions with dif- } \\
\text { ferences between } \\
\text { Healthy and ADHD } \\
\text { groups }\end{array}$ \\
\hline $\begin{array}{l}\text { Dickhaus et } \\
\text { al. }\end{array}$ & 1997 & - & EEG & $\begin{array}{l}\text { Demonstrate clinical appli- } \\
\text { cations of a wavelet net- } \\
\text { work }\end{array}$ & $\begin{array}{l}\text { Create wavelet networks, } \\
\text { use as a self-learning algo- } \\
\text { rithm }\end{array}$ & Auditory Cortex \\
\hline Heinrich et al. & 2001 & Morlet & EEG & $\begin{array}{l}\text { Demonstrate clinical appli- } \\
\text { cations of a wavelet net- } \\
\text { work }\end{array}$ & $\begin{array}{l}\text { Estimate and parametrize } \\
\text { EEG signals }\end{array}$ & Frontal Lobe \\
\hline $\begin{array}{l}\text { Yordanova et } \\
\text { al. }\end{array}$ & 2001 & Beta-Spine & EEG & $\begin{array}{l}\text { Alterations in audition } \\
\text { mechanisms of ADHD } \\
\text { volunteers }\end{array}$ & $\begin{array}{l}\text { Extract gamma burst re- } \\
\text { sponses from EEG signals }\end{array}$ & $\begin{array}{l}\text { Motor, Sensorimotor and } \\
\text { Cognitive cortices }\end{array}$ \\
\hline $\begin{array}{l}\text { Yordanova et } \\
\text { al. }\end{array}$ & 2006 & Morlet & EEG & $\begin{array}{l}\text { Theta activity and late } \\
\text { event-related theta oscilla- } \\
\text { tions are markers of } \\
\text { ADHD }\end{array}$ & $\begin{array}{l}\text { Time-frequency decompo- } \\
\text { sition of EEG signals }\end{array}$ & $\begin{array}{l}\text { Motor, Sensorimotor and } \\
\text { Cognitive cortices }\end{array}$ \\
\hline $\begin{array}{l}\text { Ahmadolou et } \\
\text { al. }\end{array}$ & 2010 & Coifman & EEG & $\begin{array}{l}\text { Demonstrate clinical appli- } \\
\text { cations of a wavelet net- } \\
\text { work }\end{array}$ & $\begin{array}{l}\text { Two: First, detect changes } \\
\text { in synchronization likeli- } \\
\text { hoods of different EEG sig- } \\
\text { nals. Second, time-fre- } \\
\text { quency decomposition of } \\
\text { EEG signals }\end{array}$ & $\begin{array}{l}\text { Whole brain (10-20 EEG } \\
\text { system) }\end{array}$ \\
\hline Lee et al. & 2010 & $\begin{array}{l}\text { Daubechies IV, } \\
\text { Coifman V, } \\
\text { Biorthogonal } 3.1 \\
\text { and sym7 (sym7 } \\
\text { was best) }\end{array}$ & EEG & $\begin{array}{l}\text { Demonstrate clinical appli- } \\
\text { cations of a wavelet net- } \\
\text { work with clustering fea- } \\
\text { tures obtained with wave- } \\
\text { let analysis and using an } \\
\text { artificial neural network }\end{array}$ & $\begin{array}{l}\text { Perform time-frequency de- } \\
\text { composition. Obtaining } \\
\text { power spectrum features. } \\
\text { Denoising EEG signals and } \\
\text { then parametrizing them }\end{array}$ & Frontal Lobe \\
\hline $\begin{array}{l}\text { Alexander et } \\
\text { al. }\end{array}$ & 2010 & Morlet & EEG & $\begin{array}{l}\text { Decreased activity in P3 } \\
\text { electrode for ADHD in au- } \\
\text { ditory and visual tasks }\end{array}$ & $\begin{array}{l}\text { Time-frequency decompo- } \\
\text { sition of EEG signals }\end{array}$ & Frontal Lobe \\
\hline $\begin{array}{l}\text { Yordanova et } \\
\text { al. }\end{array}$ & 2010 & Morlet & EEG & $\begin{array}{l}\text { Behavior fluctuations in } \\
\text { ADHD patients are double } \\
\text { with frequencies of } 12 \text { and } \\
20-30 \mathrm{~Hz}\end{array}$ & $\begin{array}{l}\text { Time-frequency decompo- } \\
\text { sition of EEG signals }\end{array}$ & $\begin{array}{l}\text { Medial Prefrontal, Poste- } \\
\text { rior Cingulate and Precu- } \\
\text { neus }\end{array}$ \\
\hline Gross et al. & 2012 & Morlet & EEG & $\begin{array}{l}\text { Slow fluctuations of the } \\
\text { theta band during face } \\
\text { recognition tasks is useful } \\
\text { to distinguish ADHD pa- } \\
\text { tients }\end{array}$ & $\begin{array}{l}\text { Extract Gamma Burst Re- } \\
\text { sponses from EEG signals }\end{array}$ & Parietal Lobe \\
\hline Hillard et al. & 2013 & Morlet & EEG & $\begin{array}{l}\text { Alertness and focus levels } \\
\text { of ADHD patients under- } \\
\text { going neuro-feedback } \\
\text { treatment improve }\end{array}$ & $\begin{array}{l}\text { Time-frequency decompo- } \\
\text { sition of EEG signals and } \\
\text { calculation of relative } \\
\text { power at different band- } \\
\text { widths of EEG signal. }\end{array}$ & Prefrontal Cortex \\
\hline $\begin{array}{l}\text { Yordanova et } \\
\text { al. }\end{array}$ & 2013 & Morlet & EEG & $\begin{array}{l}\text { Excitability of motor cor- } \\
\text { tex is similar between } \\
\text { groups, inhibition in com- } \\
\text { plex tasks is different for } \\
\text { ADHDs }\end{array}$ & $\begin{array}{l}\text { Time-frequency decompo- } \\
\text { sition of EEG signals (mu } \\
\text { band) }\end{array}$ & Motor Cortex \\
\hline $\begin{array}{l}\text { Docksteader } \\
\text { et al. }\end{array}$ & 2008 & Morlet & MEG & $\begin{array}{l}\text { Decreased de-synchrony in } \\
\text { alpha bands and decreased } \\
\text { synchrony in the beta band } \\
\text { for ADHD patients in SI \& } \\
\text { SII }\end{array}$ & $\begin{array}{l}\text { Time-frequency decompo- } \\
\text { sition of MEG signals. Par- } \\
\text { ametrization of these sig- } \\
\text { nals }\end{array}$ & $\begin{array}{l}\text { Primary and Secondary } \\
\text { Somatosensory Cortex }\end{array}$ \\
\hline Franzen et al. & 2013 & Morlet & MEG & $\begin{array}{l}\text { Different connectivity be- } \\
\text { tween sections from the } \\
\text { default mode network for } \\
\text { ADHD and Controls }\end{array}$ & $\begin{array}{l}\text { Time-frequency decompo- } \\
\text { sition of MEG signals. Par- } \\
\text { ametrization of signals ob- } \\
\text { taining phase coherence }\end{array}$ & $\begin{array}{l}\text { Default Network struc- } \\
\text { tures }\end{array}$ \\
\hline
\end{tabular}




\begin{tabular}{|c|c|c|c|c|c|c|}
\hline & & & & & $\begin{array}{l}\text { measurements (functional } \\
\text { connectivity) }\end{array}$ & \\
\hline Mairena et al. & 2012 & Morlet & $\begin{array}{l}\text { Functional } \\
\text { MRI }\end{array}$ & $\begin{array}{l}\text { Different frequency bands } \\
\text { show a strong correlation } \\
\text { with scores form the } \\
\text { ADHD tests }\end{array}$ & $\begin{array}{l}\text { Time-frequency decompo- } \\
\text { sition of resting state sig- } \\
\text { nals }\end{array}$ & All Brain \\
\hline $\begin{array}{l}\text { Anderson et } \\
\text { al. }\end{array}$ & 2016 & Haar & $\begin{array}{l}\text { Functional } \\
\text { MRI }\end{array}$ & $\begin{array}{l}\text { Low frequency physiologi- } \\
\text { cal noise fluctuations of } \\
\text { BOLD signals is corre- } \\
\text { lated with emotional meas- } \\
\text { urements in inferior ver- } \\
\text { mis }\end{array}$ & $\begin{array}{l}\text { Time-frequency decompo- } \\
\text { sition of resting state sig- } \\
\text { nals. Parametrization of } \\
\text { signals }\end{array}$ & Cerebellum \\
\hline $\begin{array}{l}\text { González et } \\
\text { al. }\end{array}$ & 2014 & Mexican Hat & $\begin{array}{l}\text { fMRI Res- } \\
\text { ting State }\end{array}$ & $\begin{array}{l}\text { Integrated spectrum of MR } \\
\text { resting state images are } \\
\text { larger for Control group } \\
\text { than ADHD }\end{array}$ & $\begin{array}{l}\text { Parametrization of resting } \\
\text { state images }\end{array}$ & Cerebellum \\
\hline Suárez et al. & 2016 & $\begin{array}{l}\text { Coiflets 1, Mex- } \\
\text { ican Hat, } \\
\text { Daubechies II \& } \\
\text { III }\end{array}$ & $\begin{array}{l}\text { fMRI Res- } \\
\text { ting State }\end{array}$ & $\begin{array}{l}\text { Demonstrate clinical appli- } \\
\text { cations of a wavelet differ- } \\
\text { entiation program while } \\
\text { altering wavelet used and } \\
\text { other parameters }\end{array}$ & $\begin{array}{l}\text { Parametrization of resting } \\
\text { state signals }\end{array}$ & $\begin{array}{l}\text { Frontal orbitofrontal, } \\
\text { Calcarine Sulcus, Lin- } \\
\text { gual gyrus, Superior Oc- } \\
\text { cipital \& Postcentral } \\
\text { Gyrus, Temporal Pole, } \\
\text { Crus I \& II }\end{array}$ \\
\hline Reiss et al. & 2015 & Daubechies I & $\begin{array}{l}\text { fMRI Res- } \\
\text { ting State }\end{array}$ & $\begin{array}{l}\text { Information derived di- } \\
\text { rectly from images can not } \\
\text { compete in accuracy with } \\
\text { scalar information derived } \\
\text { from wavelet analyses }\end{array}$ & $\begin{array}{l}\text { Parametrization of resting } \\
\text { state signals }\end{array}$ & All brain \\
\hline $\begin{array}{l}\text { Di Martino et } \\
\text { al. }\end{array}$ & 2008 & Morlet & None & $\begin{array}{l}\text { High frequencies of the re- } \\
\text { sponse time evolution are } \\
\text { larger and more variable in } \\
\text { ADHD patients }\end{array}$ & $\begin{array}{l}\text { Time-frequency decompo- } \\
\text { sition of resting state sig- } \\
\text { nals }\end{array}$ & All brain \\
\hline
\end{tabular}

\section{Discussion}

A complete summary of the works presented in this paper can be seen in Table 1. Here authors, year of publication, kind of wavelet used, neurological technique employed, biological finding, use of wavelet and brain regions studies are presented.

In general, all work which used wavelets in the field of ADHD was found to be quite recent with first papers appearing as early as in 1997. We expect much more works in the field to appear soon because of the publication of results from the ADHD challenge and maybe because of the call effect that the Mayer 2017 price to one of the wavelet developers might have.

Discussing which is the best wavelet to use for a given analysis, is an interesting subject. Some authors say that the only criteria should be the similarity between the wavelet and the signal that is going to be studied [28]. In this line of thought and considering specifically biomedical signals analyses (EEG, MEG, Resting states, etc.); there is an extensive study which compares several wavelets for these applications [29]. They calculated correlations between wavelets and signals in different segments of the signals. They then added results and averaged them. They considered that wavelets with the larger averages were the most suited for the studies. In contrast to this line of though, there are other approaches to wavelet selection. One option would be to create a new wavelet or modify an existing one (e.g. [30]). Another option is just to try different wavelets and evaluate which one produces the best results (e.g. [31]).

It is important to highlight that in this review none of the papers presented, discussed why they used a given wavelet. Furthermore, all papers except for two works performed their studies with only one wavelet. As it can be seen in Table 1 it was the Morlet wavelet which was most used, with almost $60 \%$ of the studies employed it Other wavelets that were indistinctively used were Daubechies, Harr and Coifman. One of the main reasons why this wavelet was so used is mainly practical as the Morlet wavelet is one of the oldest wavelets available. Because of this, the wavelet forms already part of some of the main software packages that are commercially available (e.g.: Matlab or Mathematica.). Furthermore, this specific wavelet has traditionally been used in the analysis of auditory and visual perception signals. And as readers can appreciate, half of the works performed auditory and perception studies. We can conclude from the different papers presented in this review, that the most convenient mother wavelet depends on the way we are studying/analyzing/obtaining the signal. Therefore, for ADHD there is not specific wavelet which provides better or worse results, but depends on the analysis.

The main application of wavelets used in papers presented in this review was its time-frequency decomposition properties. As mentioned before this property of wavelet analysis, allows them to extract a given band of frequencies from a signal. This application is widely used as it is known to be more efficient than other methods (Autoregressive analyses, Fourier transforms, Frequency distributions, etc.), especially when signals are unstable (vary in time [32]). This property was used in almost $90 \%$ of papers presented, but this was almost always done in combination with other wavelet applications. It appeared on its own just in $20 \%$ of occasions. For these $20 \%$, researchers just extracted a frequency band from EEG signals and then studied it with more classical methods, e.g. correlations with other parameters. Publications that use wavelets for this, just "happen" to be using them as they could have been using any other mathematical method for the same thing. Much more relevant, (as can be seen in Table 1 and is happening in almost $60 \%$ of works), is the ability of wavelets to parametrize signals. Parameters like: Connectivity, power calculations, phase locking, etc. are pivotal in obtaining results in their respective papers and highlighting the relevance of the use of wavelet transformation.

The neurological research tools on which wavelet analyses were mostly applied were EEG, MEG and, in a lesser role, MR. EEG work makes sense as wavelets have been largely used to filter information about this field over the past, it is a cheap technique, and data is simple to obtain. It is also the technique which has been the longest in the market. As stated by several authors in this study, quantified parameters obtained from a signal like EEG were much better to differentiate ADHD and Controls than images. This might have been tempered by the development of research with MR techniques. Furthermore, their sampling rate is smaller than that from EEG. This fact might limit the amount of information available.

Finally, it is worth commenting once again that even if they are similar in function to the Fourier transform as they decompose data into frequencies, they present the advantage of being able to decompose data sets considering time too, all this with a higher time and frequency resolution. All these facts sum to make wavelet analysis a powerful tool to address medical imaging analysis. Even though 
we have not reached a level of success based on which we can say that different neurological techniques can be trusted as a diagnostic tool, we hope that a combination neuroimaging data with wavelet and other mathematical analysis could lead us in the right way. As highlighted by the second strongest application of wavelets in this review, the parameterization of signals is the main line of work for the development of the field. Other future lines of progress will focus in: further stratification of ADHD patients into their respectively subtypes; the same as before but also considering associated comorbidities; development of better de-noising techniques; improvement of the resolution of analysis at low frequencies and search for bio-markers of the illness through signal decomposition processes. All the research performed till this moment, and the one to be done in the future, will help differentiation of ADHD as well as develop the understanding of the physiology behind ADHD.

\section{References}

[1] A Polanczyk, G., et al., The worldwide prevalence of ADHD: a systematic review and metaregression analysis. Am J Psychiatry, 2007? 164(6): p. 942-8. https://doi.org/10.1176/ajp.2007.164.6.942.

[2] Doyle, A.E., et al., Diagnostic efficiency of neuropsychological test scores for discriminating boys with and without attention deficit-hyperactivity disorder. J Consult Clin Psychol, 2000. 68(3): p. 477-88 https://doi.org/10.1037/0022-006X.68.3.477.

[3] Gualtieri C.T. and L.G. Johnson, ADHD: Is Objective Diagnosis Possible? Psychiatry (Edgmont), 2005. 2(11): p. 9.

[4] Lenartowicz, A. and S.K. Loo, Use of EEG to diagnose ADHD. Curr Psychiatry Rep, 2014. 16(11): p. 498 https://doi.org/10.1007/s11920-014-0498-0.

[5] Dickhaus, H. and H. Heinrich, EP parametrization and classification using wavelet networks--theoretical concept and medical application. Stud Health Technol Inform, 1997. 43 Pt B: p. 541-5.

[6] Heinrich H., et al., Time-on-task analysis using wavelet networks in an event-related potential study on attention-deficit hyperactivity disorder. Clin Neurophysiol., 2001. 112(7): p. 7 https://doi.org/10.1016/S1388-2457(01)00541-7.

[7] Yordanova, J., et al., Abnormal early stages of task stimulus processing in children with attention-deficit hyperactivity disorder--evidence from event-related gamma oscillations. Clin Neurophysiol, 2001. 112(6): p. 1096-108. https://doi.org/10.1016/S13882457(01)00524-7.

[8] Gross, E., et al., Induced Eeg Gamma Oscillation Alignment Improves Differentiation between Autism and Adhd Group Responses in a Facial Categorization Task. J Neurother, 2012. 16(2): p. 78-91. https://doi.org/10.1080/10874208.2012.677631.

[9] Yordanova, J., et al., Increased event-related theta activity as a psychophysiological marker of comorbidity in children with tics and attention-deficit/hyperactivity disorders. Neuroimage, 2006. 32(2): p 940-55. https://doi.org/10.1016/i.neuroimage.2006.03.056.

[10] Yordanova, J., et al., Comorbidity in the context of neural network properties. Behav Brain Sci, 2010. 33(2-3): p. 176-7. https://doi.org/10.1017/S0140525X1000083X

[11] Yordanova, J., V. Kolev, and A. Rothenberger, Event-related oscillations reflect functional asymmetry in children with attention deficit/hyperactivity disorder. Suppl Clin Neurophysiol, 2013. 62: p. 289-301. https://doi.org/10.1016/B978-0-7020-5307-8.00018-1.

[12] Ghosh-Dastidar, S., H. Adeli, and N. Dadmehr, Mixed-band wavelet-chaos-neural network methodology for epilepsy and epileptic seizure detection. IEEE Trans Biomed Eng, 2007. 54(9): p. 1545-51. https://doi.org/10.1109/TBME.2007.891945.

[13] Ahmadlou, M. and H. Adeli, Wavelet-synchronization methodology: a new approach for EEG-based diagnosis of ADHD. Clin EEG Neurosci, $2010 . \quad 41(1): \quad$ p. $\quad 1-10$ https://doi.org/10.1177/155005941004100103.

[14] Alexander, D.M., et al., Event-related wave activity in the EEG provides new marker of ADHD. Clin Neurophysiol, 2008. 119(1): p. 163-79. https://doi.org/10.1016/j.clinph.2007.09.119.

[15] Alexander, D.M., et al., Measurement of phase gradients in the EEG J Neurosci Methods, 2006. 156(1-2): p. 111-28. https://doi.org/10.1016/j.jneumeth.2006.02.016

[16] Lee, S.H., et al., Analysis of Attention Deficit Hyperactivity Disorder in EEG Using Wavelet Transform and Self Organizing Maps, in International Conference on Control, Automation and Systems 2010: Gyeonggi-do, Korea.
[17] Won-Seok, K., A method of mother wavelet function learning for DWT-based analysis using EEG signals in Sensors, 2011, IEEE, Editor 2011: Limerick, Ireland. p. 3.

[18] Hillard, B., et al., Neurofeedback training aimed to improve focused attention and alertness in children with ADHD: a study of relative power of EEG rhythms using custom-made software application. Clin EEG Neurosci, 2013. 44(3): p. 193-202. https://doi.org/10.1177/1550059412458262.

[19] Dockstader, C., et al., MEG event-related desynchronization and synchronization deficits during basic somatosensory processing in individuals with ADHD. Behav Brain Funct, 2008. 4: p. 8. https://doi.org/10.1186/1744-9081-4-8.

[20] Franzen, J.D., et al., Atypical coupling between posterior regions of the default mode network in attention. Psychiatry Neurosci. , 2013. 38(5): p. 7.

[21] Anderson, C.M., S.B. Lowen, and P.F. Renshaw, Emotional task-dependent low-frequency fluctuations and methylphenidate: Wavelet scaling analysis of 1/f-type fluctuations in fMRI of the cerebellar vermis. J Neurosci Methods, 2006. 151(1): p. 52-61. https://doi.org/10.1016/j.jneumeth.2005.09.020.

[22] Mairena, M.A., et al., Low frequency oscillations of response time explain parent ratings of inattention and hyperactivity/impulsivity. Eur Child Adolesc Psychiatry, 2012. 21(2): p. 101-9. https://doi.org/10.1007/s00787-011-0237-6.

[23] Romero Sánchez, K., et al., Wavelet analysis of MR functional data from the cerebellum., in XIII Mexican Symposium on Medical Physics201|4, AIP Conference Proceedings: León, Mexico.

[24] González Gómez, D.I., et al., Difference between healthy children and ADHD based on wavelet spectral analysis of nuclear magnetic resonance images, in XIII Mexican Symposium on Medical Physics, A.C. Proceedings, Editor 2014: León, México. p. 4

[25] Suárez García, J.G., et al. Diagnosis of ADHD children by wavelet analysis. in XIV International Mexican Symposium on Medical Physics. 2016. Mexico DF, Mexico: AIP Conference Proceedings. http://dx.doi.org/10.1063/1.4954096

[26] Reiss, P.T., et al., Wavelet-Domain Regression and Predictive Inference in Psychiatric Neuroimaging. Ann Appl Stat, 2015. 9(2): p 1076-1101. https://doi.org/10.1214/15-AOAS829.

[27] Di Martino, A., et al., Decomposing intra-subject variability in children with attention-deficit/hyperactivity disorder. Biol Psychiatry, 2008. 64(7): p. 607-14. https://doi.org/10.1016/j.biopsych.2008.03.008.

[28] Najarian, K. and R. Splinter, Biomedical Signal and Imaging Processing. 2012, Boca Raton, Florida, USA: CRC Press. 376.

[29] Rafieea, J., et al., Wavelet basis functions in biomedical signal processing. Expert Systems with Applications, 2011. 38(5): p. 11. https://doi.org/10.1016/j.eswa.2010.11.050.

[30] Imaeda, S., et al. Analysis of ER-fMRI time series with modified mother wavelet. in International Symposium on Comunications and Infromation Technologies. 2004. Sapporo, Japan. https://doi.org/10.1109/ISCIT.2004.1413837.

[31] Gandhi, T., B.K. Panigrahi, and S. Anand, A comparative study of wavelet families for EEG signal classification. Neurocomputing, 2011. 74: p. 6. https://doi.org/10.1016/j.neucom.2011.04.029.

[32] Al-Fahoum, A.S. and A.A. Al-Fraihat, Methods of EEG signal features extraction using linear analysis in frequency and time-frequency domains. ISRN Neurosci, 2014. 2014: p. 730218. 